\title{
Social Representations of Feeding People with Type-2 Diabetes Mellitus
}

\author{
Maria Marta Amancio Amorim ${ }^{1 *}$, Natalia Ramos², Maria Flavia Gazzinelli ${ }^{3}$ \\ ${ }^{1}$ University Center UNA, Belo Horizonte \\ ${ }^{2}$ Open University of Lisbon, Lisboa, Portugal \\ ${ }^{3}$ Federal University of Minas Gerais, Belo Horizonte, Brazil
}

Received: April 04, 2016; Accepted: April 27, 2016; Published: April 30, 2016

*Corresponding author: Maria Marta Amancio Amorim, University Center UNA. E-mail: martamorim@hotmail.com

\begin{abstract}
The aim of this study was to analyze the social representations of the diets 34 patients of the Brazilian public primary care service diagnosed with type- 2 diabetes mellitus, according to how they represent their identity. Free association of words was used with responses to questions to survey social representations of food. Representations of identity were adopted from a previous study with the same participants. Normal participants eat healthily, eat little, eat greens and vegetables, avoid sweets, have positive attitudes, and maintain healthy eating habits and regular blood glucose levels. Participants who accept having the disease do not eat a lot, do not eat everything, avoid sweets, have an attitude of acceptance, and maintain inadequate eating habits and uncontrolled blood glucose. Participants with difficulties do not eat everything, do not eat a lot, do not follow the diet and eat vegetables and fruits, and have negative attitudes and altered blood glucose.
\end{abstract}

Keywords: Type-2 diabetes; Health care primary; Illness and disease chronic; Self-care

\section{Introduction}

Because of the need for constant control of blood glucose, chronicity, and not having a cure, patients with type 2 diabetes mellitus (Type-2 DM) are connected to the health care system for decades, requiring continuous care with a focus on self-care nutrition, exercise, self-administration of medicines and glycemic control [1,2].

Diet is one of the most difficult challenges faced by individuals with Type-2 DM $[1,3,4]$. Because of its prohibitive nature, dietary change is the first limitation experienced by people diagnosed with Type-2 DM and is cause for stress, discrimination, and oppression. Diet is the main cause of poor control of the disease because of inadequate or incorrect information, and negative attitudes and social representations of individuals with Type- 2 DM [5].

Despite their ability to adapt to self-care and glycemic control, maintaining these is not easy for most people with Type-
2 DM because, when diagnosed with the disease, the structure of everyday life and what sustains it are interrupted [6]. The disease causes disruption of identity, which might be permanent and impact lifestyle. In the patient's relationships with others, identity can be constructed or reconstructed [7]. Based on these assumptions, Amorim, et al. [8] studied the identity of individuals with Type-2 DM using the theoretical framework of representations of identity as a dynamic phenomenon, comprised of representations of oneself as well as group representations, constructed and modeled on social relations, assumed and experienced by sick individuals [9]. Among the results of this study, some patients with Type-2 DM thought that they were normal, others accepted the disease, some lived life with difficulties, and others did not accept having the disease [8].

The aim of this therefore was to analyze the social representations of the diets of patients with Type-2 DM, according to how they represent their identity.

\section{Methods}

The study was undertaken at a Basic Health Care Unit (BHU) in the city of Belo Horizonte, in the southeastern state of Minas Gerais, Brazil. Patients with Type-2 DM were invited to participate in the study; those who had chronic complications from the disease, such as blindness, amputation of a limb, and/ or infections were excluded. Thirty-four individuals participated, of whom $97 \%$ were aged 50 or more, $32 \%$ were men, and $68 \%$ were women. The study participants signed a free and informed consent form, and the project was approved by the research ethics committee of the Federal University of Minas Gerais and the Municipal Secretary of Health of the City of Belo Horizonte.

To capture spontaneous thoughts and feelings about food, each participant was asked to say five words or phrases in response to the question: "When you think of 'the diabetic diet,' what comes to mind?" The participant was then asked to indicate the phrase that they considered most important and their justification for this choice. To complement the data on to food, 
seeking to capture dietary practices, the participants were asked: "How do you feel about your diet?"

The interviews were recorded, and the participants' responses were transcribed in their entirety, and interpreted by means of Bardin's thematic-categorical content analysis [10], including pre-analysis, coding, and processing of results. Interpretation of the data was performed by the researchers to obtain compatible descriptions to confirm data reliability.

The categories were analyzed using Moscovici's theory of social representations, [11]. The data on food and dietary practices were presented and analyzed together as one complex practical representation [12]. The statements of each category of the complex practical representation of a participant as it exemplifies identity were described in the results in the form of literal quotes, thereby giving life to the representation. Study participants' representations of identity, obtained from the earlier study, were: "normal"; "accept the disease"; "do not accept the disease;" and "have difficulties" [8].

\section{Results}

\section{Study participants' social representations of food}

The study participants' social representations of food were built around social interactions to give meaning to diet, a complex concept, making it something more familiar. The categories of social representations of food raised were: "eat healthily"; "eat vegetables and fruits"; "eat little"; "avoid sweets"; "don't eat everything"; "don't eat too much;" and "don't follow the diet." The participants who thought that they were "normal"; "accepted the disease"; "had difficulty;" and "did not accept the disease" represented their food in one of these categories. Below is one participant's discourse on food as it represents her identity and dietary practice.

\section{Normal participants' social representations of food}

Participants classified as normal predominately think that they have a "normal life", "feel well," and "have control" of their blood glucose. Participants who are "normal and think that they have a normal life" establish new life habits, and are able to adapt to the variability and instability of daily life to attain normality and equilibrium. Participants who are "normal and feel well" do not experience symptoms of chronic illness, and establish new life habits to attain normality. Those participants who are "normal and believe that they control" their blood sugar variabilities and the possible complications arising from lack of control managed to transform the disease into a normal lifestyle [8].

These normal participants $(n=15)$ represent their diets in the categories "eat healthily" $(n=3)$, "eat less" $(n=4)$, "eat fruits and vegetables" ( $(n=4)$, and "avoid sweets" $(n=4)$, discussed below.

Eat healthily: Health is very important in the life of "normal" participants who, concerned about maintaining glycemic control, orient themselves according to ideas disseminated in society, in different media, about eating "healthful things" to represent their diet. Thus, one participant related healthful diet and glycemic control:

Seek to eat healthy things. It is a healthy diet, because I should accept my body's metabolism so that it stays at a more normal level. Once we get sick it's hard to get better, especially for diabetics.

The participant who made the statement above believes that her glucose can be normal if she accepts that her body is affected by Type- 2 DM. Because the disease has no cure, her body will not return to the previous state of normalcy; however, she is able to find the dynamic balance between health and disease by adhering to the precepts of a healthful diet. To be healthful, her diet depends on quantitative and qualitative balance:

We don't strictly follow the diabetic diet. I don't have separate food. I can eat everything, but everything in proportion, right? I eat bread with light margarine, drink whole milk, coffee with artificial sweetener. In the morning, if there's no bread, I eat a cookie. Yesterday for lunch I made rice, beans, vegetables, and roasted chicken (my husband loves it, but I try to eat a small piece with less fat, as the broth is very greasy and I don't eat it). I eat two bananas a day, and an orange or apple. I avoid making sweets. Sometimes I make a snack in the afternoon, sometimes I eat a banana. Dinner is the same. I make fried kibbeh, once a week. I drink beer Friday, Saturday, and Sunday.

This participant's diet is not as "strict" as she desires. She eats healthful foods such as light margarine, vegetables, and fruits, and expresses care to divide her food throughout the day and consume fatty foods and alcohol in balanced portions. When she says that she eats less fatty foods, this participant categorizes foods, taking into account the quantity and quality of fats. When she mentions that she sometimes substitutes her snack with a banana, she demonstrates concern about the qualitative aspect of the food in regard to carbohydrates.

Eat less: For "normal" participants, control is focused on the amount of food and expressed as eating less, an idea chosen to represent the diet of the patient. Below is the statement of one participant who directs his normal life to reduced eating:

Normal. Ever since I learned that I am diabetic in 1996, I have had a normal life. I reduced the amount I ate from two plates to one. The doctor told me to cut down, but never gave me a diet to follow. The doctor from the company health plan told me that because I travel all the time, it is good for me to suck on a candy, to not become hypoglycemic.

Because the daily diet of this participant includes the same foods he consumed before he was diabetic, he represents it as normal. He does not consider eating less a diet, which he understands to be a list of acceptable and prohibited foods and quantities. In practice he eats normally:

My eating is normal, I never received a diet. I reduced the amount I ate and began to eat half. I'm a driver, and day in and day out I travel to Vitória. I stay in a hotel and return the next day at 9 p.m. On the way back I eat three pieces of fruit that I picked up at the hotel.

The participant above did not receive a diet containing foods 
that he can and cannot eat, and continues to eat "normally", that is, to eat the same foods he consumed prior to the disease. He reeducated himself and reduced his food by half. In addition to quantity, quality is an element of his dietary choices when he eats fruit during long trips. Rich in simple carbohydrates and fibers, these foods help to control blood glucose levels until the next meal.

Eat fruits and vegetables: Eating vegetables and fruits, a recommendation present in the media as an element of healthful eating, is the social representation of the food of this group of normal patients. The following statement of one "normal" participant emphasizes "eating vegetables and fruits":

I make separate food for me, rice and meat. I eat a lot of vegetables and fruit. The only thing that I eat is papaya, oranges, and bananas. I love bananas. I don't like apples, because they make me hungry. Every once in a while, I buy watermelon and pineapple from time to time, for a change. Not often.

In addition to eating large quantities of these foods, this participant reports differential care in preparing her food separately. In practice her diet is based on adhering to treatment and control over her urges, because she feels pleasure in eating fried food:

Before I was more careless: "If I eat this, I'm really going to die"-my father spoke like that. So I thought, Let me go easy on things to eat. I want to live. I haven't cut out everything. I eat fried foods. Now I know more or less what I can eat. I'm aware. Now, at least, I practically eat by appointment. Every three hours, I graze all the time. I cut down a lot. At 10 a.m. I eat a mashed banana with oats and milk. At lunch, I eat rice, beans, meat, and raw and cooked vegetables, all with little oil.

This patient assigns meaning to her dietary practice when reporting that, because she wants to live, she has adopted an attitude of control, that is, "take it easy on what I eat." In the past, she was negligent with her diet and complicit with her father's attitude: "If I eat this, I'm really going to die." At the time of the study, she had decided to eat the foods that she representsvegetables and fruits-in addition to eating every three hours, and the fried food she likes so much.

Avoid sweets: A strong belief circulating in the common imagination is that people with Type-2 DM cannot eat sweets. One "normal" participant believes that avoiding sweets is a way to protect herself from the consequences of consuming this forbidden food:

I stopped making and eating sweets. Sweets, I feel pleasure when eating sweets. I stopped drinking juice, because I like sweets. I don't like sweetener. I decreased the amount of coffee I drink, and add a little skimmed milk.

This participant likes and feels pleasure in eating sweet foods, which cause feelings of reward and wellbeing. She describes what she does not eat, and how she does not prepare the foods that she has a harder time resisting. Because she does not like artificial sweetener, she sought an alternative to sweeten her coffee with sugar in the milk. Day by day, she has radically moved away from eating sweets:

In the morning, I drink coffee with milk. Before lunch, I eat a cookie. My lunch is early, and I eat rice, beans, vegetables, and a little piece of meat. There are days that I eat well, and there are days that I do not have the pleasure of eating, and then I make instant pasta. I'm hungry, but I don't have the urge/will. At lunch, I eat bread with butter and coffee with milk. At dinner, it's the same as lunch. At 10 at night, I eat a snack, bread and a cookie. I don't buy sweets anymore, to not have them at home. I stopped drinking juice, because I like juice with sugar added. I make French fries one or two times a month, pasta, once a month. I like beer; I drink three to four bottles with six people.

Guided by the standard of avoiding food that gives her pleasure, this participant does not buy sweets or drink sweetened juice. In search of pleasurable sensations, she sporadically consumes other foods that she likes, such as French fries, pasta, and beer. However, on certain days her diet is marked by a lack of pleasure in eating. She divides her meals and eats vegetables.

\section{Social representations of food of study participants who accept having the disease}

Participants who "accept having the disease" are unable to live with the different conflicts arising from Type-2 DM, and accept that they are sick [8]. These participants' $(n=5)$ representations of food are based on "don't": "don't eat a lot" $(n=2)$ and "don't eat everything" $(n=3)$.

\section{Don't eat a lot}

In contemporary society, "eating a lot" is considered to be an unhealthy behavior, because an excessive amount of food is a risk factor for obesity, Type-2 DM, hypertension, and cardiovascular disease. To avoid poor health, one participant represents her diet in the negative with the expression "don't eat a lot." People with Type-2 DM cannot go for long without eating, reports the participant, who "accepts having the disease":

Sometimes I eat sweets and candy. When I'm away from home, and go a long time without eating anything, my stomach feels ill, so I suck on a piece of candy and drink water.

This participant explains that when she goes a long time without eating, his stomach feels ill, a sign that there is a lack of glucose in his blood. "His remedy" to combat the sense of malaise is to suck a piece of candy-a common belief in the popular imagination. Thus, sugar, traditionally banished from the diet of these people, becomes an ally to be introduced into the body to fight the harm. The information that "eating at regular intervals prevents hypoglycemia" has yet to be popularly known among the population. She thinks that people with Type-2 DM should not eat a lot:

Food at home is in the normal amount. The family eats low fat and little food; it is balanced. In 1990, I cut back; I lost weight, because I strictly followed the diet. I experienced a hunger like no other; two spoons of rice and beans, that big chunk of meat, no, a small piece of meat, sautéed vegetables. My mother was a diabetic, 
and I told her I/she would follow the diet. Then she died, so there is the emotional factor. My blood sugar varies a lot. I went to the doctor and told her that I was feeling weakness on my diet. It gets worse; but then it improves. She told me that I don't need to be so strict. I could follow the diet without abusing it. There are days when I snack all day.

With the experience of following a strict diet under the supervision of her mother, this participant who "accepts having the disease" felt weak and learned from her doctor that she should not be so strict, and so she chose not to eat a lot and "not abuse" food. In contrast to the strict diet, there are days when she "snacks all day," contrary to the ideal food plan for patients with Type-2 DM which is to eat small meals and snack on food between meals. As a result of this practice, her blood glucose is not in the healthy range and varies greatly.

\section{Don't eat everything}

In layperson's speech, the language that science uses to talk about nutritional notions of variety and balance of nutrients is translated as "eat everything." Below is the statement of one participant who "accepts having the disease." His discourse is focused on what he cannot eat and the impact of these foods on his sick body:

\section{Conscious eating}

We have to be aware of what we eat; we can't eat anything. If I'm going to eat a food that is not okay, I might get sick.

This participant classifies foods according to what is not okay to eat, and those that cause physical harm to people with Type-2 DM. It is likely that "don't eat everything" was engraved in the mind of this participant when he accepted the prohibitive diet prescribed by his physician. The dietary practice of this participant is guided by not eating foods that make his sick body feel ill:

Look, I think the person has to be aware of what they eat. You can't eat anything you want. I will follow the guidance of the doctor, because I'm a patient. I can't get off the diet, because I know that I'll get sick. But my food isn't food for sick people; it will avoid illness, it does not cause disease. I eat bread every day. With cheese or salami. I use skim milk and artificial sweetener. I eat rice, beans, vegetables, and meat. I take my lunch box. I eat two oranges after lunch and dinner. Dinner is the same, with less.

This participant's account is typical of a patient who thinks that they are "conscious" when patiently listening to the doctor's advice "don't eat everything." He manages his illness by accepting a diet based on the representation that the food he eats "is not sick food." He reports that his food does not make the Type-2 DM worse, and avoids complications from the disease. He reports eating only three meals per day (breakfast, lunch, and dinner), and goes a long time without eating between meals.

\section{Social representations of participants who have difficulty}

Participants who "have a life of difficulties" are those who, after being diagnosed with Type- $2 \mathrm{DM}$, tried to adapt to the treatment, yet encountered difficulties with self-care [8]. These participants express negative feelings and attitudes. People with Type-2 DM who believe that they have difficulty $(n=8)$ represent their diet in the negative categories "don't eat a lot" ( $n=3)$, "don't eat everything" ( $\mathrm{n}=2)$, and "don't follow the diet" (2). One participant represents her diet as eating vegetables and fruits and, contrary to normal, has difficulty putting her thinking into practice.

\section{Don't eat a lot}

Participants who think they have difficulty represent their diet in the negative category "don't eat a lot." For one participant, "don't eat a lot" was expressed in the following manner:

I don't feel anything. I feel good, I eat normally; I'm not one to eat exaggeratedly. I know what I can't eat.

This participant thinks that she knows which foods she cannot eat, and thinks that she eats without exaggerating. When reviewing her practices, she reports that she does not "eat many meals":

I had breakfast; I ate a piece of cheese. I like it melted in the pan. Now, I just eat lunch. I don't go without dinner. I eat three meals. I feel good making my food for my children. I eat normally, without exaggerating.

She feels good when preparing meals for her children, and thinks she eats "normally, without exaggerating," when reporting that she eats three times a day, a practice inadequate for people with Type-2 DM, who need to snack between meals.

\section{Don't eat everything}

Some participants who think they have difficulties anchor themselves in the category "don't eat everything" to give an account of the complex meaning of food. One participant's statement below illustrates this representation: "Don't eat what you can't." This participant uses a double negative to reinforce the notion of "don't eat everything." From an account of his dietary practices, it is noted that this participant has difficulty eating fruit, which he believes he cannot eat:

I get up at 7 a.m., and eat bread with coffee. I make rice; I eat a lot-four spoons, a ladle of beans, a vegetable, a salad, cooked meat, and a piece of chicken. Then I eat dinner at 7 p.m., what I had for lunch and in the same portion. I like fruit a lot, but it is very expensive. I like papaya a lot, but it's sweet. Can I? Banana, can I? And watermelon? And orange, can I? And mango, can I? Every once in a while, I drink juice or soda at lunch. The diet is good, right?

This participant, who "has difficulties," appropriates knowledge from common sense, that is, that people with Type2 DM cannot eat fruits because they have sugar, combining this knowledge with his financial situation. In this way, she constructs the idea that he cannot eat fruits because they are expensive and sweet. Thus, she does not snack on fruit between meals, of which he only consumes three per day. 


\section{Don't follow the diet}

In line with the thought that people with Type-2 DM have difficulties implementing the food plan, "don't follow the diet" is how some participants who claim that they "have difficulties" represent their diet. The statement below is one participant's representation:

\section{I wasn't able to do the diet}

I don't do it like I should, because of my work as a sales representative. I work in the morning, and in the afternoon I'm home. I wish I had the willpower to do the diet.

Simply knowing the actions he should take was not enough for him to implement "the diet," because he expressed feelings of being incapable. For this participant, his work hinders adhering to the diet because it prevents him from eating at home. In practice, he does not follow the diet because he has difficulties:

I do not do this diet; I am not the type to eat all day. I fill my plate and eat the same meal as before I was diabetic. Once a week I eat a sweet; I feel the urge to eat sweets.

For this study participant, adhering to the diet means eating all day; thus, he reports that he is unable to do the diet, because he works outside the home. He adds: "I fill my plate and eat the same meal as before I was diabetic." This thought is correct, because people with Type-2 DM should eat several times a day, dividing up their food intake. Sweets are part of his diet, and he eats them once a week.

\section{Eat fruits and vegetables}

One participant who "has difficulties" developed the habit of eating fruits and vegetables before getting Type-2 DM because she liked them. She represents her diet as eating fruits and vegetables, because these foods provide her with pleasant taste sensations:

I like vegetables. My entire life, I have liked to eat vegetables. If I can, I eat two types of vegetables; I just don't like the taste of cucumber. I lost my mother at the time I was going to take the exams. I was not strictly following the diet because of the hospital; I stayed at the hospital for 20 days, so the [exam] results went up.

Not defining himself as normal, this participant has difficulty putting into practice his representation of identity in terms of eating fruits and vegetables:

During the week, I buy food at the local vegetable and fruit store, and I eat well. I don't have enough money to buy so much fruit, so I buy bananas. I really like greens and vegetables, and take care to buy these, but if there are none, I do my best. On the subject of food, we try, but we're not perfect. We take the drug perfectly, exactly as we should, but on food we end up stumbling. If I go three hours without eating, I start trembling with dizziness and weakness. If I go out, I put a cookie or candy in my bag, as those girls directed us to. I'm trying. Food is the only thing I falter on.

This participant developed a taste for fruits and vegetables, which are an essential element of a healthful diet for patients with Type-2 DM. However, she points out that her food purchasing is conditioned by her financial situation, which is not the case with medicines distributed free of charge by the public health network. She eats "correctly" when she makes food purchases, but when the food runs out, she puts aside her daily routine of eating vegetables and eats what she has at home. Most likely, when this participant suffers symptoms of hypoglycemia, she has not divided her meals throughout the day.

\section{Social Representations of Diets of Patients Classified as Not Accepting that They Have Type- 2 DM}

In the face of the instability and variability caused by diabetes, nonaccepting participants complain or react to rules, and are reluctant to adopt them [8]. As with patients who accept the disease, the nonaccepting participants $(n=6)$ represented their diet in the negative categories "don't eat a lot" $(n=2)$ and "don't eat everything" ( $n=2)$. Two participants represented their diet as eating vegetables; however, in practice, they eat foods that are prohibited.

\section{Don't eat a lot}

For one nonadhering participant, "don't eat a lot" means not eating too much and not eating too little. This means not eating exaggeratedly and not adhering to a strict diet.

Never exaggerate. When I started the treatment, the doctor gave me a diet so that I would never exaggerate and never diet too much. I don't follow that diet, because people who follow strict diets die more depressed.

The consequences of following a strict diet have a dramatic significance for this nonaccepting participant, who believes that it can lead to early death. This patient thinks that the diet should not be either an excess or a shortage of food. In practice, she thinks she does not eat a lot:

\section{I feel fine, thank God}

Never go on a diet, and never eat exaggeratedly. I stick to the limit, the way he taught me. I do the exam and, if it is high, I control $i t$. In the morning, I like a piece of salted bread with margarine, a thin slice of cheese and coffee with artificial sweetener. At lunch, I like rice, beans, a piece of meat, chicken, endive, lettuce. I buy candy to not eat. I like peach jam. I drink juice with artificial sweetener, but I am not that into juice. I usually drink lemon soda with sugar. There are days when I snack: a biscuit, a scone, coffee. Dinner, I warm up the same thing.

Anchored in the antinomies of "never exaggerate" and "never diet too much," this participant does not adhere to a strict diet, but controls her food intake in her own way, for example, based on her test results and the knowledge that she judges to be correct, she eats sweets and drinks soda every once in a while. This participant reports eating breakfast and then lunch, a practice that is not in adherence with a proper diet for an individual with Type-2 DM.

\section{Don't eat everything}

For the nonadhering participants, "don't eat everything" 
was built based on restrictions. According to one participant, "Don't eat pasta, because we cannot eat pasta." This participant's discourse is based on the widely-held belief that people with Type-2 DM cannot eat pasta. Pastas, breads, and vegetables that grow underground have been prohibited by doctors for a long time, since before the advent of insulin. This prohibition constitutes a crystallized representation, evidencing the role of foods as bearers of symbolic meanings that permeate the collective imagination. This participant characterizes her dietary practice as marked by restrictions and lack of pleasure:

I cut out bread and I'm eating cream crackers. I drink skim milk. Between meals, I eat a banana or pear. I eat rice, beans, a little bit of steak, and green salad. I love green salad, raw collard greens, endive, leafy greens; I always make these. In the afternoon, I eat a piece of fruit. For my evening snack, I like cookies with milk, coffee, or fruit. If I eat at night, I get sick. I feel a lot of body aches. I make the food, but eating right-I do not feed myself well. I don't get that urge. I do it, but when I do, I do not like it. I live with my husband. I would eat better if it were someone else's food. I don't like to cook much.

She does not eat at night, and the obligation to prepare food on a daily basis brings her dissatisfaction. Thus, she thinks that she does not eat correctly. With a strong belief that permeates her thinking, she has replaced bread with cream crackers, which are in the same group, are high in fat and commonly known as a diet food.

\section{Eat fruits and vegetables}

To have representational thinking in terms of vegetables and fruits does not mean eating healthily, because a proper diet must contain qualitative and quantitative aspects. One nonaccepting participant represents her diet as "eating vegetables and fruits":

My diet has juice and vegetables. I like apples, bananas, oranges, and occasionally a pear. The apple is the most important and then comes the pear. I eat cake when I go to my mother's house. I live with my daughter and my husband, and then I go off the diet. I have to control; I have to eat a little roll and have lunch. At my mother's house I go off the diet.

After adhering to the diet in her own home and eating vegetables and fruits, this participant visits her mother and goes off the diet, eating foods that are not recommended for patients with Type-2 DM. She reports eating a roll and then having lunch, going a long time without eating between breakfast and lunch, a practice that can raise blood glucose.

\section{Discussion}

In living with the disease, the participants in the different groups ("normal", "accept having Type-2 DM", "have difficulties," and "don't accept Type-2 DM") built distinct subjective meanings to rediscover (or not) themselves as belonging to this new group of "diabetics," accepting the disease or not, and even recreating (or not) the dietary practices prescribed for people with Type-2 DM. It is specifically this ability to build new subjective meanings and new representations, through new emotions and symbolic expressions that enabled each of these subjects to gain new life options in the face of new life situations.

Social representations are a subjective production that includes a complex web of subjective meanings organized in relation to a theme or human action. Subjective meaning represents the way in which reality becomes subjective, and is always fed by a lived experience; however, this takes a single characteristic from the subjective meanings that intervene in this process in which they participate, not only the meanings produced in the context of the action, but meanings historically configured in that subject [13]. These subjective meanings on which the participants of this study supported themselves greatly influenced the different practices of dietary self-care. These people organize their routine with practices that they understand, accept, and share with other people, which ensures the stability of the world in which these participants believe and the maintenance of identity and security. The implications of the social representations of food for each group of participants with DM2 according to how they represent identity will be shown below.

\section{Normal}

The fact that these participants perceive themselves as normal instead of sick, and represent the food for patients with Type-2 DM as healthful, might lead to the development of positive attitudes, accountability for their health, and adopting effective self-care dietary behavior.

Some participants translate being healthy despite the disease into positive attitudes manifested by their own ability to control the disease, to overcome difficulties, and to be able to live a normal life [14]. Some studies on Type-2 DM relate positive attitudes to adhering to treatment and maintaining glycemic control with the best self-care actions [15], in addition to reducing stress from the disease, and providing greater responsiveness to treatment, confidence in the multidisciplinary health care team, improved self-esteem, a sense of self-efficacy, and more positive perceptions of health and social acceptance [16].

Participants who accepted their disease and made positive changes in their life should ideally have accepted the chronicity of the disease. Ideal acceptance of a disease consists of a psychological state in which the disease is part of one's perception of the reality and is not viewed as a limiting factor. This state involves the individual's ability to reorganize him - or herself and others regarding social and family relationships and rational, affective, and emotional aspects related to everyday life [17].

\section{Accepting the disease}

These participants recognize that they have Type-2 DM, coexist with the symptoms of the disease passively, and accept prohibitive medical prescriptions. In this sense, despite the different reasons why they perceive themselves as sick patients, they have attitudes of acceptance in regard to various conflicts arising from the disease that affects them and their self-care actions. 
When diagnosed with Type-2 DM, the individual might lose everything on which they base their identity, the social position conferred by marital status, profession, and other elements within different social groups and assume the identity of being sick, which pervades the entirety of their spatial, temporal, and relational spheres [18]. The patient is placed in a position of nonaccountability for their health, which implies exemption from social responsibilities, inability to care for oneself, a desire to be well, and a duty to seek out and cooperate with medical treatment [19]. In the study conducted by Francioni \& Silva, [20], the process of acceptance of the "diabetic identity" and its consequences was critical, but insufficient in itself to change the behavior of people with Type-2 DM.

\section{Having difficulties}

These participants struggle to live with Type-2 DM because they have a hard time practicing self-care actions. In addition, they believe it is hard to reveal the disease to people, who do not know them, and to live with high glucose levels and control the Type-2 DM for the rest of their lives. In this sense, despite the different reasons that they see themselves with a life full of difficulties, they have negative and pessimistic attitudes regarding the disease and self-care actions.

Pessimistic people expect negative results and tend to attribute their problems-for example, adapting to dietary recommendations, permanent control of desires, and feelings and anxieties-to general and external factors [3,21-24]. It is possible that less optimistic people with DM2 and those with signs of negative affect, when faced with difficulties, do not make continuous effort toward achieving their objectives, neglecting treatment [25-29]. These people show a worsening of glycemic control, worse adherence to therapy, and increased risk of longterm complications [30,31].

Participants who claimed to lead a difficult life with diabetes faced impediments to self-care culminating in negative feelings and attitudes regarding the disease. Such people see the disease as a situation threatening their normal and effective performance of roles and tasks for which they have been socialized [32], and this can create situations of exclusion within social and family interactions [33]. It is possible that, because people with DM2 who experience difficulties lack confidence in the future, they do not make continuous efforts to overcome adversities and achieve their goals [29], thus neglecting self-control and selfcare, particularly regarding diet/food intake.

\section{Nonacceptance}

These participants do not accept having Type-2 DM, do not adjust to it, and think this chronic and irreversible illness is not part of them, and that they do not have the right and the freedom to feel healthy when compared with people who do not have Type-2 DM [8]. In this sense, despite the different reasons why they perceive themselves as nonadherents, they have attitudes of dissatisfaction in relation to the disease, and to the events of their daily lives and self-care actions required.

Diagnosis of Type-2 DM can lead to suffering a loss of self and a struggle to accept the new self [34]. The "patient," with a new identity as someone who is sick, assigns control of their treatment to health care professionals, and establishes a relationship of obedience, submission, strong dependence and inactivity, faithfulness and loyalty [32,35-37]. Some people believe that Type- $2 \mathrm{DM}$ is not a serious disease that leads to serious consequences and impacts lifestyle [38,39]. People with Type-2 DM undergo successive changes and states of imbalance related to biophysical changes and psychological readjustments that often lead to situations of wear and dissatisfaction with life when assuming a self-care routine [40].

The feelings of unease, dissatisfaction, repression, low self-esteem, and lack of pleasure impede them from building a "normal" identity. During treatment, these individuals with Type-2 DM experience feelings and behaviors that hinder the acceptance of their chronic health condition, and consequently the adoption of healthful habits to cope with the limitations of illness [41].

Amorim, et al. [42] proposed an educational intervention based on social representations from a review of models of behavioral change. To illustrate the model they used part of the empirical representations of identity and feeding this present study. They selected to adopt the health approach process action, because this model considers the motivational stage the social representations about the contingencies that influence health behavior desired, expected outcomes, risk perception and intention as a decision-making process by which an individual may adopt a preventive measure or change risk behavior for others. In the volitional phase we included the resolution of problems. Social representations of acceptance to be diabetic and those related to feeding and self-efficacy influence the cognitive construction of action plans.

\section{Conclusions}

The ways in which the participants with Type-2 DM understand their illness and act in terms of self-care are defined by the representations they construct about social objects that bother them and involve their surroundings, such as identity and food. The participants had removed from their social reality elements that were able to give body and consistency to their representations of identity and social representations of food.

The dimensions of social representation information and image facilitated understanding in relation to the management of information concerning the participants' identity and diet. This information, available according to their levels of knowledge and through symbols or images, is used by the participants to understand their social reality, feel part of a common world, and recognize themselves as subjects in the construction of their own reality. The other dimension of social representation, attitude toward the disease, was highlighted in the participants' statements to explain the overall orientation in relation to objects of representation, namely identity and food. The participants inform and represent themselves solely after having taken a position or attitude about the given object, and acting on the basis of this positioning. 
In this sense, social representation configures itself as an essential element to be considered in working toward diabetes prevention and promoting the health of individuals with Type- 2 DM

\section{Limitations}

The aim of study was to analyze the social representations of the diets of persons with Type-2 DM, according to how clients of a primary health care network represent their identity. We suggest that new studies be performed with people with Type-2 DM in other settings, using the same methodological approach. As a consequence of this study, we suggest investigating the existence of an association between biochemical markers, duration and disease and representations of the diets and identity of persons with Type-2 DM.

\section{Funding}

The authors disclosed receipt of the following financial support for the research, authorship, and/or publication of this article: Maria Marta Amancio Amorim disclosed receipt of financial support from Capes Demanda Social and Capes-Process BEX 4757/11-4.

\section{References}

1. Cyrino AP. [Between science and experience-A cartography of selfcare in diabetes]. São Paulo, Brazil: Editora da Universidade Estadual de São Paulo; 2009.

2. American Diabetes Association. Standards of medical care in diabetes-2014. Diabetes Care. 2014;37 Suppl 1:S14-80. doi: 10.2337/ dc14-S014.

3. Anderson RM, Goddard CE, Garcia R, Guzman JR and Vasquez F. Using focus groups to identify diabetes care and education issues for Latinos with diabetes. Diabetes Educator. 1998;24(50):616-625.

4. Pontieri FM and Bachion MM. [Beliefs of diabetic patients about nutritional therapy and its influence on their compliance with treatment]. Ciência \& Saúde Coletiva. 2010;15(1):151-160. doi: http://dx.doi.org/10.1590/S1413-81232010000100021.

5. Motta, D. G. [Nutrition education \& type 2 diabetes - sharing knowledge, tastes and feelings]. Piracicaba, Brazil: Jacinta Editores; 2009.

6. Bury M. Chronic illness as biographical disruption. Sociology of Health and Illness. 1982;4(2);167-182. doi:10.1111/1467-9566. ep11339939.

7. Williams SJ. Chronic illness as biographical disruption or biographical disruption as chronic illness? Reflections on a core concept. Sociology of Health \& Illness. 2000;22 (1): 40-67. doi:10.1111/14679566.00191.

8. Amorim MMA, Ramos N, Brito MJM and Gazzinelli MF. Identity Representations of People with Diabetes. Qualitative Health Research. 2014;24(7): 919-922.

9. Deschamps JC and Moliner P. A identidade em psicologia social-dos processos identitários às representações sociais [The identity in social psychology-The identity processes to social representations]. Petrópolis, Brazil: Vozes. 2009

10. Bardin L. Análise do conteúdo [Analysis of content]. Lisbon, Portugal: Edições 70. 2010.
11. Moscovici S. [Psychoanalysis, its image and its public]. Petrópolis, Brazil: Vozes. 2012

12. Wagner W. [Description, explanation and method in research of social representations]. In: P.A. Guareschi, S. Jovchelovitch (Eds.). [Texts in social representations]. Petrópolis, Brazil: Vozes; 1994. p.149-186.

13. Rey FLG. [Social representations like subjective production: impact on hipertension and cancer]. Psicologia: Teoria e Prática. 2006;8(2):6985.

14. Silva LS. Practical knowledge of health - the logic of healthy in daily life. Porto, Portugal: Edições Afrontamento. 2008.

15. Torres-López TM, Sandoval-Diaz M, and Pando-Morineo M. ["Blood and sugar": social representations of diabetes mellitus by chronic patients in Guadalajara, Mexico]. Cadernos de Saúde Pública. 2005;21(1):101-110.

16. Steed L, Cooke D and Newman S. A systematic review of psychology outcomes following education, self-management and psychological interventions in diabetes mellitus. Patient Education \& Counseling. 2003;51(1):5-15.

17. Dijkstra A, Buunk AP, Toth G, Jager N. Psychological adjustment to chronic illness: The role of prototype evaluation in acceptance of illness. Journal of Applied Biobehavioral Research. 2008;12(3-4):119140. doi:10.1111/j.1751-9861.2008.00018.x

18. Collière MF. [Promote life]. (3rd ed). Portugal: Ed. Lisboa. 1999.

19. Robinson D. The process of becoming ill. Londres: Routeledge \& Kegan Paul; 1971.

20. Francioni FF, and Silva DMG. [The acceptance process in living with diabetes mellitus: considerations on the environmenbt's influence]. Texto Contexto \& Enfermagem. 2002;11(3):36-43.

21. Snyder CR. Hypothesis there is hope. In: C.R. Snyder (Ed.). Handbook of hope: theory, measures and applications. (pp. 3-21). USA: Academic Press. 2000. p. 3-21.

22. Carver CS and Scheiner MF. Optimism. In: CR Snyder, SJ Lopez. (Eds.). Handbook of positive psychology. USA: Oxford University Press; 2002. p. 231-243.

23. Snyder CR, Rand KL and Sigmon DR. Hope theory. In: C.R Snyder, S.J. Lopez (Eds.). Handbook of positive psychology. USA: Oxford University Press; 2002. p. 3-9.

24. Reivich K, and Guilham J. Learned optimism the measurement of explanation style. In: S.J Lopez, C.R Snyder. (Eds.). Positive psychology assessment. A handbook of models and measures. USA: American Pshycological Association; 2003. p. 57-74.

25. Anderson RJ, Freedland KE, Clouse RE, Lustman PJ. The prevalence of comorbity depression in adults with diabetes: a meta analysis. Diabetes Care. 2001;24(6):1069-1078. doi:10.2337/diacare.24.6.1069.

26. Kruse J, Schmitz N, Thefeld W; German National Health Interview and Examination Survey. On the association between diabetes and mental disorders in a community sample: results from the German National Health Interview and Examination Survey. Diabetes Care. 2003;26(6):1841-1846. doi:10.2337/diacare.26.6.1841.

27. Nichols GN and Brown JB. Unadjusted and adjusted prevalence of diagnosed depression in type 2 diabetes. Diabetes Care. 2003;26(3):744-749. doi:10.2337/diacare.26.3.744.

28. Gois C. [Psychological adaptation and metabolic control]. Arquivos de Medicina. 2004;18 (suplemento 1):4-55.

29. Silva I, Pais-Ribeiro J, and Cardoso H. [Difficulty seeing the positive 
side of life? Stress in diabetic patients with and without chronic complications]. Psychological Analysis. 2004;3(22):597-605.

30. Cienchanowski PS, Katon WJ and Russo JO. Depression and diabetes: impacto of depressives symptoms on adherence, function and costs. Archivos of Internal Medicine. 2000;160(21):3278-3285. doi:10.1001/archinte.160.21.3278.

31. Matos AP. [Study of some emotional and cognitive aspects of diabetes] Psiquiatria Clínica. 2000;21(3):173-182.

32. Carapinheiro G. [Scenarios medical strategies in hospital]. Critical Review of Science Social. 1987;23:141-156.

33. Dias MRA. [The veteran patient: Forgotten knowledge in health systems]. Analysis Psychological. 1999;3(17):499-512. Retrieved from www.scielo.oces.mctes.pt/pdf/aps/v17n3/v17n3a07.pdf

34. Ockleford E, Shaw RL, Willars J and Dixon Woods M. Education and self-management for people newly diagnoses with type 2 diabetes: a qualitative study of patients`views. Chronic Illn. 2008;4(1):28-37. doi: $10.1177 / 1742395307086673$

35. Ribeiro JLP. Psychology and Health]. Lisboa, Portugal: CLIMEPSI; 1998.
36. Paúl C, and Fonseca, A. Psicossociologia da Saúde. [Social Psychology of Health]. Lisboa, Portugal: CLIMEPSI; 2001.

37. Serra MN. [Learning to be patient - patient learning processes in hospital]. Loures, Portugal: Lusociência; 2005.

38. Murphy E and Kinmonth, AL. No symptoms, no problem? Patients understandings of non-insulin dependent diabetes. Family Pract. 1995;12:184-192.

39. Rayman KM and Ellison GC. Home alone: the experience of women with type 2 diabetes. Who are new to intensive control. Health Care Women Int. 2004;25(10):900-15.

40.Amorim IL and Coelho R. Diabetes mellitus tipo 2 e sintomas psicopatológicos. [Type II diabetes mellitus and psycopathological symptoms]. Psic., Health \& Diseases. 2008;9(2):319-333.

41. Péres DS, Franco LJ, Santos MA, Zanetti ML. [Social representations of low-income diabetic women according to the health-disease process]. Rev Lat Am Enfermagem. 2008;16(3):389-95.

42. Amorim MMA, Ramos N, Bento IC and Gazzinelli MF. [Educational intervention in Diabetes Mellitus]. Psicologia, Saúde \& Doenças. 2013;14 (1):168-184. 